\title{
Analyzing Drivers' Mental Patterns Using Q-Methodology
}

\author{
Abbas Sheykhfard1, Farshid Reza Haghighi', Mostafa Soltaninejad2 ${ }^{2}$, Ali Karji ${ }^{3}$ \\ ${ }^{1}$ Department of Civil Engineering, Babol Noshirvani University of Technology, Babol, Iran \\ ${ }^{2}$ Jacobs Engineering Group, Omaha, NE, USA \\ ${ }^{3}$ Department of Architectural Engineering, Pennsylvania State University, University Park, PA, USA \\ Email: A.sheykhfard@nit.ac.ir
}

How to cite this paper: Sheykhfard, A., Haghighi, F.R., Soltaninejad, M. and Karji, A. (2020) Analyzing Drivers' Mental Patterns Using Q-Methodology. Journal of Transportation Technologies, 10, 169-181. https://doi.org/10.4236/jtts.2020.102011

Received: February 20, 2020

Accepted: March 27, 2020

Published: March 30, 2020

Copyright $\odot 2020$ by author(s) and Scientific Research Publishing Inc. This work is licensed under the Creative Commons Attribution International License (CC BY 4.0).

http://creativecommons.org/licenses/by/4.0/ (c) (i) Open Access

\begin{abstract}
The human factor is the most important cause of road accidents. Investigating the drivers' mental patterns can lead to a better understanding of the factors that affect drivers to make a mistake and thus increase the likelihood of an accident. In this study, mental patterns of drivers as a human characteristic are determined through a questionnaire survey. To do this, 166 participants (18 - 65 years) were asked to express their opinion on the possible effect of 25 factors on the occurrence of accidents. These factors were selected through the investigation of the accident database during the last three years in different areas of the case study. To analyze the data extracted from the survey, Q-methodology was used. The results of the factor analysis showed that there are 5 mental patterns among the participants. Based on the driver's opinion, human factors and road conditions were the most and least influential accident-generating items, respectively. The most significant reason for accidents determined by drivers was human errors including 1) unauthorized overtaking, 2) unauthorized speed, 3) driver distractions (such as cell phone), and 4) driver physical disability (such as visual impairment). Moreover, the failure of the vehicle was mostly reported as another influential contributor to accidents. It is worth mentioning that the results of this study can be used to minimize accidents resulted from drivers' behavioral errors by suggesting strategies for enhancing their performance through new manuals which is a step towards a safer road.
\end{abstract}

\section{Keywords}

Human Factor, Driver Mental Pattern, Q-Methodology, Factor Analysis, Questionnaire

\section{Introduction}

World Health Organization reported that more than 1.35 million people are 
killed and 50 million are injured worldwide each year due to traffic accidents [1]. In order to minimize accidents, the behavior of drivers should be studied. Increased distance between homes and workplaces, as a result of urbanization in modern life besides population growth, has increased the need for transportation. The most remarkable consequence of this need is the increased enthusiasm of people to use personal vehicles during urban and suburban trips, resulting in an abnormal increase in the number and severity of traffic accidents [2] [3] [4]. Generally, the main factors affecting accidents can be classified into four groups: road (geometrical and traffic flow characteristics), vehicles (vehicle ability, technical defects of elements), human factors (driver' characteristics, behaviors, and physiological abilities), and the environment (weather conditions) [5] [6] [7]. These factors interact with each other to affect the occurrence of accidents, and if one of these factors becomes unstable, the possibility of an accident will be increased. Based on the previous crash reports, the human factor has been identified as the main reason for accidents. Therefore, studying the behavior of drivers as one of the most influential human factors in the occurrence of accidents can play an essential role in preventing them. In this study, the mental patterns of the drivers as a human factor in the accident's occurrence were studied.

\section{Problem Importance and Research Goal}

Analyzing the behavioral parameters of drivers, pedestrians, and traffic characteristics of accident points have a pivotal role in identifying the effective factors to reduce the number of accidents [8] [9] [10] [11]. Based on accident databases, causes related to vehicle, environment, and road factors affecting the occurrence of accidents have been investigated by researchers through various studies [14]-[23]. Previously, various studies have focused on the causes of accidents, especially human factors as a considerable factor of accidents [4] [5] [6] [7] [17] [20] [21] [22]. For instance, Young et al. (2018) reported the possible effects of texting while driving as a human error factor [23]. Recently, in addition to questionnaire-based and accident-based database studies, some studies have been conducted to improve pedestrian safety through data collection. Sheykhfard and Haghighi (2018) examined a set of conflicts between drivers and pedestrians to describe a set of behaviors that can lead to an increased probability of collision between them. They evaluated the NDS of 29 participating drivers by installing three in-vehicle cameras on urban roads. 289 vehicle-pedestrian conflicts were identified. Evaluation of video data extraction showed that some mistakes stemmed from pedestrians or drivers led to an increased chance of collision. An example of this mistake was the aggressive behaviors of pedestrians, such as running on the road or starting to cross the street without looking at the route were one of them. For driver's error, distracted drivers were noticeable, and the reason for distraction was either talking to the occupants or listening to music [24]. In another study, a set of drivers' actions to prevent pedestrians from colliding in divided and undivided roads was assessed. Evaluation of 701 conflicts 
through the NDS of 66 participants showed that drivers performed actions such as decelerating, accelerating, and braking to a complete stop and changing lanes to prevent pedestrians on both roads [25].

However, there is a gap in evaluating the influential parameters from the perspective of the driver, especially the mental behavior of drivers. In the present study, the mental behavior of drivers is assessed by analyzing the data extracted from the questionnaire surveys. For this analysis, the Q-methodology is used. Q-methodology is a tool that enables researchers to identify and classify perceptions and beliefs, as well as classify individuals into different groups according to their perceptions [15] [19]. This leads to the evaluation of drivers' mental patterns of behavior and thus identifying the reasons of accident occurrence. The main purpose of this technique is to reveal different patterns of thinking and not to count the number of people who have different opinions. A significant difference in Q-methodology compared to other conventional analysis methods is that the $\mathrm{Q}$ approach evaluates individuals instead of variables that leads to achieving a kind of typology [15].

The aim of this research is to determine influential factors that lead drivers to make mistakes and thus increase the possibility of an accident. Moreover, the results of this study can be effective in reducing the accidents caused by drivers' behavioral errors through suggesting strategies for enhancing their performance which boosts the safety of roads.

Despite numerous studies on accidents, there is a lack of information regarding the mental pattern of drivers using Q-methodology to categorize the causes of accidents from the perspective of drivers themselves. The benefit of this study can specifically improve road traffic safety because determining drivers "mentality patterns can lead to a general mentality pattern. This general pattern can directly help to improve drivers" performance by minimizing driver behavioral error and thus reducing accident occurrence.

\section{Methodology}

\subsection{Q-Methodology}

Q-methodology is a research technique used in psychology and social sciences to study people's viewpoints. This method was developed by psychologist William Stephenson. He invented it to answer this question: "What makes people unique?”. Instead of recognizing similar attitudes in people, Stephenson tried to understand a unique attitude in them [15]. His idea is based on a common factor analysis approach. This analysis is based on selecting $\mathrm{N}$ individuals and measuring $M$ attributes in each of them and then calculating the intrinsic correlation by using Spearman's method or any other factor analysis methods. Subsequently, this new approach to the subject is the opposite of former methods, which were revolved around measuring $\mathrm{N}$ characteristics in $\mathrm{M}$ individuals and calculating the intrinsic correlation between them and then extracting the pertinent factors. In other words, unlike conventional research methods that were selecting $\mathrm{N}$ 
people and measure $\mathrm{M}$ attributes, in the Q-Methodology, M people are selected to measure $\mathrm{N}$ attributes of themselves.

Contrary to the traditional methods where the selected individuals have a passive attitude toward measurement, the Q-methodology is based on an active attitude that needs to be measured [19]. This methodology was founded on the basis that not only the perceptions of the world but also the real world is unique to each of them. Q-methodologists opted for epistemological constructivism by accepting that humans act on images of reality rather than reality itself. This approach is close to the cognitive approach, which believes that behaviors should be examined through information processing derived from stimuli, not stimuli themselves [15] [19].

The $\mathrm{Q}$ diagram is a chart that is given to the participants to show their viewpoints by placing different items into different cells inside the chart. In this diagram, there is a gradual range where participants sort the items based on the degree of agreement or disagreement with the graph. Typically, the degree of symmetry ranges from $-\mathrm{x}$ to $+\mathrm{x}$ where negative values show disagreement and positive values represent an agreement with the item content. A value of zero is assigned to neutral or uncertain. In the $\mathrm{Q}$ diagram, items can be distributed either in a free or forced method. Forced distribution requires participants to use a spectrum with a specific grading and to place some items at each point of the spectrum. In a free distribution, the participants have more freedom to act regularly. For example, where there is no restriction, they can place the items in the range of any order they wish. Therefore, the form of distribution of the items is not predetermined and each participant will create their own choice. Based on previous studies, forced distribution is better to be used in the Q-methodology [26] [27]. Accordingly, a forced distribution is used for Q-methodology in the present study.

To evaluate the Q-methodology, factor analysis and varimax method are typically utilized for the analysis of the results. Factor Analysis is an analytical method used to identify the number and nature of latent variables responsible for variability in the data. Varimax rotation is a common technique that attempts to minimize the complexity of the factors by making large loadings larger and small loadings smaller within each factor [28].

\subsection{Applying Q-Methodology in the Case Study}

According to the statistics of the Iranian Legal Medicine Organization [29], the roads between the cities of Lorestan province especially those around Khorramabad are one of the most dangerous roads with high-risk of accident probabilities. In the first step of current study, accident recorded data on the case study were investigated using the accident database. Accordingly, this resulted in the identification of 25 main items that were selected as the main factors to prepare the questionnaire items that are shown in Table 1. In the next step, we designed a questionnaire survey and distributed among 166 drivers with a maximum age of 65 and a minimum of 18 years old. The drivers were asked to rate the risk of each 
Table 1. Questionnaire items.

\begin{tabular}{|c|c|}
\hline Question & Items \\
\hline 1 & Improper monitoring of traffic police \\
\hline 2 & Defect of traffic control tools such as signs \\
\hline 3 & Sudden changes in road width along the route \\
\hline 4 & Inappropriate weather conditions \\
\hline 5 & Non-standard road width \\
\hline 6 & Failure to comply with the rules by the driver \\
\hline 7 & Unauthorized overtaking \\
\hline 8 & Unauthorized speed \\
\hline 9 & Driver physical disability such as poor vision \\
\hline 10 & Drug and Alcohol \\
\hline 11 & Lack of sufficient driver skills \\
\hline 12 & Non-standard road curve \\
\hline 13 & Damage to asphalt pavements such as slippage cracking or road pits \\
\hline 14 & Failure to observe standard longitudinal distance with other vehicles \\
\hline 15 & External factors of driver distraction such as advertising on the sidewalk stores \\
\hline 16 & Internal factors of driver distraction such as cell phone \\
\hline 17 & Driver drowsiness \\
\hline 18 & Not paying attention to the right of another road users \\
\hline 19 & Vehicle technical defect \\
\hline 20 & No road shoulder \\
\hline 21 & Agricultural and cattle traffic \\
\hline 22 & Non-standard path lighting \\
\hline 23 & Unauthorized pedestrians crossing the road \\
\hline 24 & Improper path alignment \\
\hline 25 & Nonstandard Input and Output on road \\
\hline
\end{tabular}

item causing an accident. In this regard, participants were asked to show the extent they agree or disagree with each item on the occurrence of an accident by placing the items in the graph of $\mathrm{Q}$ from +4 (extremely effective) to -4 (extremely ineffective). Furthermore, zero indicates the lack of knowledge or belief of the participant for the impact of the item on the accident.

In the current case study, in order to determine different mental patterns, data extracted from questionnaires were evaluated using factor analysis. These data were information filled by participants about the possible effect of the questionnaire items on the possibility of accidents that scored using the Q-methodology. Afterward, to simplify the analysis process varimax rotation was applied. Accordingly, questionnaire items were associated, and the pertinent factors were considered. 


\section{Results and Discussion}

\subsection{Drivers' Mental Patterns}

After distributing the questionnaire survey, 166 participants stated their viewpoints on the 25-item representing the most influential factors in the accident occurrence. By placing each of these items into the cells with different scores in the form of Q-methodology, they determined the impact of each item according to their mental perspective. Extraction and analysis of the different mental patterns ultimately identified the five most common mental patterns among the participants.

The quantitative diagrams of mental patterns are shown in Figure 1. The triangular shape of this figure explains the extent to which each item has an impact on an accident from the participants' viewpoint. The cell number indicates the item number of the questionnaire and the number on the horizontal axis shows the impact of the items. Some items have a strong impact $(+4)$, while others have the least impact (-4).

As shown in Figure 1, participants were given a 9-degree spectrum for 25

\begin{tabular}{|c|c|c|c|c|c|c|c|c|}
\hline & & & & 13 & & & & \\
\hline & & & 9 & 24 & 25 & & & \\
\hline & & 1 & 6 & 16 & 11 & 22 & & \\
\hline & 3 & 2 & 4 & 19 & 12 & 23 & 8 & \\
\hline 20 & 5 & 17 & 15 & 18 & 14 & 7 & 10 & 9 \\
\hline \multicolumn{9}{|c|}{ The first mental pattern } \\
\hline & & & & 15 & & & & \\
\hline & & & 13 & 2 & 1 & & & \\
\hline & & 17 & 18 & 12 & 4 & 10 & & \\
\hline & 3 & 16 & 20 & 11 & 5 & 15 & 7 & \\
\hline 12 & 18 & 19 & 21 & 9 & 6 & 14 & 8 & 16 \\
\hline \multicolumn{9}{|c|}{ The Second mental pattern } \\
\hline & & & & 17 & & & & \\
\hline & & & 12 & 20 & 21 & & & \\
\hline & & 1 & 13 & 3 & 11 & 7 & & \\
\hline & 6 & 14 & 2 & 4 & 5 & 8 & 10 & \\
\hline 24 & 18 & 25 & 15 & 22 & 23 & 9 & 16 & 19 \\
\hline \multicolumn{9}{|c|}{ The third mental pattern } \\
\hline & & & & 24 & & & & \\
\hline & & & 25 & 4 & 1 & & & \\
\hline & & 12 & 8 & 22 & 3 & 14 & & \\
\hline & 2 & 13 & 10 & 6 & 17 & 15 & 9 & \\
\hline 20 & 23 & 21 & 11 & 7 & 18 & 16 & 19 & 7 \\
\hline \multicolumn{9}{|c|}{ The fourth mental pattern } \\
\hline & & & & 22 & & & & \\
\hline & & & 2 & 18 & 8 & & & \\
\hline & & 5 & 3 & 21 & 15 & 9 & & \\
\hline & 1 & 4 & 23 & 17 & 19 & 12 & 7 & \\
\hline 11 & 13 & 6 & 25 & 24 & 20 & 14 & 16 & 10 \\
\hline-4 & -3 & -2 & -1 & 0 & +1 & +2 & +3 & +4 \\
\hline
\end{tabular}

Figure 1. Final mental patterns based on Q-methodology evaluation. 
items to place the items within the spectra. The numbers on the horizontal axis indicate the degree of relevance of the item to the likelihood of an accident occurring and the sign of that type of relationship (positive or negative). Considering Figure 1, it seems participants were really conservative to use the highest and lowest threshold because they have only selected one item in +4 and -4 degrees and five items in the zero degree as a neutral opinion, which means lack of information for those contributors. To better understand this figure and evaluate the participants' viewpoint, Table 2 presented. This table summarizes the participants' most influential and least influential accident-generating items categorized in five patterns.

According to the table, the first mental pattern is based on the common mentality and perspective of this mental model, the human error has been selected as the main cause of an accident. From the group's viewpoint, the driver's physical problems, such as driver's vision impairment, especially for the elders, were factors that cause the drivers to malfunction in conditions of poor vision. On the other hand, the participants' subjective and psychological imbalance caused by drug and alcohol use as risky drivers were identified as a contributory risk factor. Moreover, sleep pills and painkillers were other factors reported in this mental pattern. Another important factor that was the main cause of the high incidence of accidents in this mental model is the unauthorized speed, which, according to many studies in the field of traffic safety, can cause accidents of varying severity. Finally, the participants identified the issues of road factors as having little impact on the occurrence of accidents.

Table 2. The most and least influential items in each of the mental patterns.

\begin{tabular}{|c|c|c|}
\hline \multirow{2}{*}{ Pattern } & \multicolumn{2}{|c|}{ Accident-generating items } \\
\hline & Most influential & Least influential \\
\hline 1 & $\begin{array}{l}\text { - Driver physical disability such as poor } \\
\text { vision } \\
\text { - Drug and Alcohol } \\
\text { - Unauthorized speed }\end{array}$ & $\begin{array}{l}\text { - No road shoulders } \\
\text { - Non-standard road width } \\
\text { - Sudden changes in road width along the route }\end{array}$ \\
\hline 2 & $\begin{array}{l}\text { - Internal factors of driver distraction } \\
\text { such as cell phone } \\
\text { - Unauthorized overtaking } \\
\text { - Unauthorized speed }\end{array}$ & $\begin{array}{l}\text { - Non-standard road curve } \\
\text { - Sudden changes in road width along the route } \\
\text { - Not paying attention to the right of another } \\
\text { road users }\end{array}$ \\
\hline 3 & $\begin{array}{l}\text { - Vehicle technical defect } \\
\text { - Drug and Alcohol } \\
\text { - Internal factors of driver distraction } \\
\text { such as cell phone }\end{array}$ & $\begin{array}{l}\text { - Improper path alignment } \\
\text { - Failure to comply with the rules by the driver } \\
\text { - Not paying attention to the right of another } \\
\text { road users }\end{array}$ \\
\hline 4 & $\begin{array}{l}\text { - Unauthorized overtaking } \\
\text { - Vehicle technical defect } \\
\text { - Driver physical disability such as poor } \\
\text { vision }\end{array}$ & $\begin{array}{l}\text { - No road shoulders } \\
\text { - Defect of traffic control tools such as signs } \\
\text { - Unauthorized pedestrians crossing the road }\end{array}$ \\
\hline 5 & $\begin{array}{l}\text { - Drug and Alcohol } \\
\text { - Internal factors of driver distraction } \\
\text { such as cell phone } \\
\text { - Unauthorized overtaking }\end{array}$ & $\begin{array}{l}\text { - Lack of sufficient driver skills } \\
\text { - Damage to asphalt pavements such as slippage } \\
\text { cracking or road pits } \\
\text { - Improper monitoring of traffic police traffic }\end{array}$ \\
\hline
\end{tabular}


The second mental pattern was similar to the common mentality and viewpoint of the first mental group. Attendants in this group believed that the human factor is the main cause of the accident. In their view, the variables that cause drivers to be distracted from traffic flow were the main source of drivers' error and malfunction in sensitive situations. Texting and talking on the cell phone have been recognized as a significant factor in the driver's distraction. On the other hand, being in a hurry condition due to inadequate time management by drivers, such as worrying about being on time at work, results in drivers to be distracted. This ultimately leads to a lack of aptitude and a lower level of consciousness of the driver for changes in traffic on the route. In this mental pattern, unauthorized speed was once again identified as one of the main links in the drivers' chain of errors and mistakes in causing accidents.

The third mental pattern was based on the fact that human factors solely cannot be the primary cause of accidents. Participants believed that although the use of substances such as alcohol and distracting factors such as cell phones reduce drivers' concentration and ability and ultimately lead drivers to the poor performance, the other share of accidents is due to the weakness of the vehicle's brake system. The issue in places where drivers need to slow down, such as approaching curves or intersections, can result in an accident due to the malfunction of the vehicle.

The fourth mental pattern was human and vehicle factors. The vehicle factor caused by the damage of the tire can result in a reduced level of sufficient contact between the tire and the pavement. Ultimately, this can lead to inadequate and timely braking insensitive driving conditions. From the perspective of people with this mental pattern, road factors such as defects or lack of pavement marking, and signposts will not have much effect on the drivers' error. In fact, they believed that drivers can perform different functions if they are sufficiently skilled in driving. Furthermore, based on participant's perspective, skilled drivers' can alert while traveling which helps them to overcome such insufficiencies and ultimately make a proper decision while driving.

The fifth mental pattern was based on the mentality of this group. The drivers' error in evaluating the traffic flow condition due to the use of alcohol or drug and distraction caused by talking on the cell phone are the main contributing factors. Unauthorized overtaking and unauthorized lateral distance are other important drivers' performance impairment. In the view of these people, despite the problems at the level, such as slippage cracking or road pits, skilled drivers can reduce the possible error with their proper performance.

\subsection{Factor Analysis for Q-Methodology Results}

In this section, the details of how five patterns were selected through factor analysis are explained. Based on varimax rotation that used for analyzing 166 questionnaires, five patterns were identified. In other words, overall, the five general patterns could represent the pattern of the 166 participants in terms of 
the causes of accidents.

Table 3 shows the rotating factor matrix. According to this matrix, the people in each of the five mental patterns were identified. One criterion in factor analysis is the selection of a factor with large factor loadings (more than 0.7) even though the number of people under the threshold is small. Factor loading is basically the correlation coefficient for the variable and factor. Factor loading shows the variance explained by the variable on that particular factor. Generally, 0.7 or higher factor loading represents that the factor extracts sufficient variance from that variable [28].

Table 4 shows the analyzed data using factor analysis for these patterns. The total variance values in the table are given by which the factor analysis identifies five mental models. It can be seen that these five patterns together account for about $94 \%$ of total variances.

\subsection{Findings and Comparison to Previous Studies}

Human factors and road properties were the most and least influential accident-generating items based on driver's opinion, respectively. Although vehicle and environment are other factors that can affect accidents, participant drivers only selected vehicle as the other most influential factor for accidents. The environmental factor was not the area of drivers' interest since it was not in any of the influential items of the five patterns. The human factor is known as the main

Table 3. Rotated matrix of patterns.

\begin{tabular}{cccccc}
\hline \multirow{2}{*}{ Participant } & \multicolumn{5}{c}{ Pattern } \\
\cline { 2 - 5 } & 1 & 2 & 3 & 4 & 5 \\
\hline 1 & 0.114 & -0.215 & 0.816 & -0.029 & -0.117 \\
2 & -0.213 & 0.312 & 0.230 & 0.926 & 0.114 \\
3 & 0.035 & 0.122 & 0.148 & 0.955 & 0.055 \\
4 & 0.795 & -0.293 & -0.211 & 0.198 & -0.065 \\
5 & -0.072 & 0.906 & -0.202 & 0.174 & -0.315 \\
166 & $\ldots$ & $\ldots$ & $\ldots$ & $\ldots$ & $\ldots$ \\
\hline
\end{tabular}

Table 4. The result of the factor analysis.

\begin{tabular}{|c|c|c|c|c|}
\hline \multirow{2}{*}{ Pattern } & \multicolumn{4}{|c|}{ Rotation Sums of Squared } \\
\hline & Most influential item category & Total & Percent of variance & The cumulative percentage \\
\hline 1 & Human factor & 13.114 & 37.214 & 37.214 \\
\hline 2 & Human factor & 9.254 & 21.119 & 58.333 \\
\hline 3 & Human and vehicle factors & 6.215 & 14.406 & 72.739 \\
\hline 4 & Human and vehicle factors & 4.230 & 11.931 & 84.670 \\
\hline 5 & Human factor & 3.880 & 9.314 & 93.984 \\
\hline
\end{tabular}


factor in accidents [1]. The important aspects of human errors have been stated as the principal reason for road accidents in some studies [30] [31]. Driving is a circle of actions interconnected in complicated systems. An incorrect interpretation of the road will result in improper performance by the driver. Yet, the essential feature of the performance suggests that the drivers must not be confused by other internal or external factors. Previous studies have reported the negative impact of internal distraction factors such as a cellphone [29] [30], or talking to passengers [24], as well as eating and drinking [30] [31] on doing a proper performance by the driver. The effect of external tools, such as traffic signs [32] [33] or digital billboards [7] on driver distraction and the likelihood of an accident has also been reported. The effects of other factors such as using drugs and alcohol on the drivers' behavior such as driving at unauthorized speeds or overtaking have been stated in the previous studies [32] [33]. However, in this study, one of the important factors that increase the effects of those factors is the drivers' physical disability such as poor vision. This can lead to poor decision-making and performance at the right time by the driver. Another important point to be noted is the fact that in this study evaluating drivers' mental patterns has been addressed on the probable factors affecting driving errors resulting in accidents. Therefore, the results of the present study can provide a better understanding of the set of factors that increase the potential for driving errors and mistakes. Regarding other factors related to vehicle, environment, and road, it is interesting to note that road characteristics were not essential to form the driver's opinion. This is because these factors were labeled as the least influential factor in all of the patterns. This also was confirmed by other studies [34] [35]. Although a driver can be affected by vehicle deficiency, improper road conditions, severe environmental conditions, and the ability to control the occurrence of an accident through a concentrated and healthy driver is crucial.

\section{Conclusions}

In the present study, mental pattern of drivers is evaluated through Q-methodology. The results of the factor analysis indicated that the occurrence of five different mental patterns among the participants had the highest effect. These patterns are unauthorized overtaking, unauthorized speed, driver distractions such as cell phone use, and impaired vision. Most of these patterns are considered as human errors. Moreover, participants identified road pavement distress and vehicle safety failures as potential contributors to accidents.

It is worth mentioning that the results of this study can be used by safety agencies for future studies on the effect of human factors since these factors were selected by the drivers themselves. Moreover, recognizing these patterns is expected to help improve the experts' knowledge of designing roads based on standard principles. Finally, the result of this paper can boost the drivers' perception about the causes of accidents through training processes. Based on the most influential accident-generating scenarios of this study, the some practical 
and traffic safety-related recommendations can be proposed including: 1) A virtual training environment can be created using virtual reality viewing systems and 360-degree videos to train road users' behaviors and evaluate their performances in various scenarios; 2) Seminars or training courses for families, students, teachers, and administrators on road safety topics can be conducted so as to boost the knowledge of society; 3) Advertisement banners and billboards can be installed to inform the people about the consequences of driving at unauthorized speeds and overtaking; 4) The consequences of using drugs and alcohol through the installation of banners or the media and the Internet can be informed; 5) Greater focus on enforcing traffic regulations such as the use of speed cameras and increase in traffic fines for offender drivers can be proposed; 6) Standard principles during constructing roads, especially the roads with curved trajectory, can be audited in the black spots; and 7) The quality of vehicle controlling systems must be improved to enhance driver performance through advanced driver assistance systems.

\section{Conflicts of Interest}

The authors declare no conflicts of interest regarding the publication of this paper.

\section{References}

[1] WHO (2018) Global Status Report on Road Safety. http://www.who.int/violence_injury_prevention/road_safety_status/2018/en

[2] Akbari, A. and Haghighi, F. (2019) Traffic Calming Measures: An Evaluation of Four Low-Cost TCMs' Effect on Driving Speed and Lateral Distance. IATSS Research. https://doi.org/10.1016/j.iatssr.2019.07.002

[3] Papadimitriou, E., Theofilatos, A. and Yannis, G. (2013) Patterns of Pedestrian Attitudes, Perceptions and Behaviour in Europe. Safety Science, 53, 114-122. https://doi.org/10.1016/j.ssci.2012.09.008

[4] Soltaninejad, M., Stremel, D., Schwasinge, B., Heugh, M., Simon, D., Jablonski, D., Sheykhfard, A. and Soltaninejad, M. (2020) Evaluating Effect of Pavement Marking on Traffic Operation of Interchange Merging and Diverging Areas Using Synchro/SimTraffic-A Case Study in USA. International Journal of Innovative Research in Technology, 6, 110-118.

[5] Jones, E.G., Soltaninejad, M. and Ponce de Leon, C. (2019) Work in Progress: Moving from Outside to Inside-Traffic Engineering Field Exercises through Virtual Reality. ASEE Annual Conference \& Exposition, Tampa, 15-19 June 2019, 8. https://peer.asee.org/33576

[6] Bakhtiari, S., Zhang, T., Zafian, T., Samuel, S., Knodler, M., Fitzpatrick, C. and Fisher, D.L. (2019) Effect of Visual and Auditory Alerts on Older Drivers' Glances toward Latent Hazards while Turning Left at Intersections. Transportation Research Record, 2673, 117-126. https://doi.org/10.1177/0361198119844244

[7] Sheykhfard, A. and Haghighi, F. (2020) Driver Distraction by Digital Billboards? Structural Equation Modeling Based on Naturalistic Driving Study Data: A Case Study of Iran. Journal of Safety Research, 72, 1-8.

https://doi.org/10.1016/j.jsr.2019.11.002 
[8] Razi-Ardakani, H., Mahmoudzadeh, A. and Kermanshah, M. (2019) What Factors Results in Having a Severe Crash? A Closer Look on Distraction-Related Factors. Cogent Engineering, 6, Article ID: 1708652. https://doi.org/10.1080/23311916.2019.1708652

[9] Ghamami, M. and Shojaei, M. (2018) Introducing a Design Framework for a Multi-Modal Public Transportation System, Focusing on Mixed-Fleet Bike-Sharing Systems. Transportation Research Record: Journal of the Transportation Research Board, 2672, 103-115. https://trid.trb.org/view/1497386

https://doi.org/10.1177/0361198118799170

[10] Haghani, M., Jalalkamali, R. and Berangi, M. (2018) Assigning Crashes to Road Segments in Developing Countries. Proceedings of the Institution of Civil Engineers- Transport, 172, 299-307. https://doi.org/10.1680/jtran.17.00099

[11] Khaloei, M. and Habibian, M. (2017) Tour Complexity and Transportation Demand Management: A Focus on CBD Work Tours.

https://trid.trb.org/view/1439760

[12] Khaloei, M., Ranjbari, A. and MacKenzie, D. (2020) Analyzing the Shift in Travel Modes' Market Shares with the Deployment of Autonomous Vehicle Technology. 99th Annual Meeting of the Transportation Research Board, Washington DC, 12-16 January 2020, 1-16.

[13] Mahmoudzadeh, A., Razi-Ardakani, H. and Kermanshah, M. (2019) Studying Crash Avoidance Maneuvers Prior to an Impact Considering Different Types of Driver's Distractions. Transportation Research Procedia, 37, 203-210. https://doi.org/10.1016/j.trpro.2018.12.184

[14] Razi-Ardakani, H., Mahmoudzadeh, A. and Kermanshah, M. (2018) A Nested Logit Analysis of the Influence of Distraction on Types of Vehicle Crashes. European Transport Research Review, 10, 44. https://doi.org/10.1186/s12544-018-0316-6

[15] Stenner, P. and Marshall, H. (1995) A Q Methodological Study of Rebelliousness. European Journal of Social Psychology, 25, 621-636. https://doi.org/10.1002/ejsp.2420250603

[16] Karji, A., Woldesenbet, A. and Khanzadi, M. (2017) Social Sustainability Indicators in Mass Housing Construction. 53rd ASC Annual International Conference Proceedings, Proceedings, Seattle, April 2017, 762-769.

[17] Karji, A., Woldesenbet, A., Khanzadi, M. and Tafazzoli, M. (2019) Assessment of Social Sustainability Indicators in Mass Housing Construction: A Case Study of Mehr Housing Project. Sustainable Cities and Society, 50, Article ID: 101697. https://doi.org/10.1016/j.scs.2019.101697

[18] Jabbari, P., Khaloei, M. and MacKenzie, D. (2019) Estimating Potential Demand for Long-Distance Electric Vehicle Travel in Washington State. 98 th Annual Meeting of the Transportation Research Board, Washington DC, 13-17 January 2019, 1-7.

[19] Stenner, P. and Watts, S. (2003) Q Methodology, Quantum Theory and Subjectivity. Operant Subjectivity, 26, 155-173.

[20] Jabbari, P., Khaloei, M. and MacKenzie, D. (2018) Locating Fast Charging Stations for Safe and Reliable Intercity Electric Vehicle Travel in Washington. 97 th Annual Meeting of the Transportation Research Board, Washington DC, 2018, 1-36.

[21] Khaloei, M. and Habibian, M. (2016) Assessing the Impacts of Transportation Demand Management Policies on Mode Choice Behavior of Car Commuters with Simple Work Tours. World Conference on Transport Research, Shanghai, 10-15 July 2016, 1-14.

[22] Zou, T., Khaloei, M. and MacKenzie, D. (2020) Effects of Charging Infrastructure 
Characteristics on Electric Vehicle Preferences of U.S. Private Car Owners: A Comparative Analysis between New and Used Car Buyers. 99th Annual Meeting of the Transportation Research Board, Washington DC, 12-16 January 2020, 1-15.

[23] Young, K.L., Lenné, M.G., Salmon, P.M. and Stanton, N.A. (2018) The Impact of Texting on Driver Behaviour at Rail Level Crossings. Accident Analysis \& Prevention, 118, 269-276. https://doi.org/10.1016/j.aap.2018.05.002

[24] Sheykhfard, A. and Haghighi, F. (2018) Behavioral Analysis of Vehicle-Pedestrian Interactions in Iran. Scientia Iranica, 25, 1968-1976.

[25] Sheykhfard, A. and Haghighi, F. (2019) Performance Analysis of Urban Drivers Encountering Pedestrian. Transportation Research Part F: Traffic Psychology and Behaviour, 62, 160-174. https://doi.org/10.1016/j.trf.2018.12.019

[26] Beck, S.J. (1962) The Q-Sort Method in Personality Assessment and Psychiatric Research. Archives of General Psychiatry, 7, 230-231. https://doi.org/10.1001/archpsyc.1962.01720030076023

[27] Cottle, C.E. and McKeown, B. (1980) The Forced-Free Distinction in Q Technique: A Note on Unused Categories in the Q Sort Continuum. Operant Subjectivity, 3, 58-63.

[28] Hatcher, L. (1994) A Step-by-Step Approach to Using the SAS System for Factor Analysis and Structural Equation Modeling. SAS Publishing.

[29] Iranian Legal Medicine (2019) Iranian Legal Medicine Organization. http://www.lmo.ir/web_directory/53999-\%D8\%AA\%D8\%B5\%D8\%A7\%D8\%AF\%D 9\%81\%D8\%A7\%D8\%AA.html

[30] Papantoniou, P., Papadimitriou, E. and Yannis, G. (2015) Assessment of Driving Simulator Studies on Driver Distraction. Advances in Transportation Studies, 35, 129-144. https://trid.trb.org/view/1356710

[31] Yannis, G., Papadimitriou, E., Karekla, X. and Kontodima, E. (2010) Mobile Phone Use by Young Drivers: Effects on Traffic Speed and Headways. Transportation Planning and Technology, 33, 385-394. https://doi.org/10.1080/03081060.2010.494030

[32] Edquist, J., Horberry, T., Hosking, S. and Johnston, I. (2011) Effects of Advertising Billboards during Simulated Driving. Applied Ergonomics, 42, 619-626. https://doi.org/10.1016/j.apergo.2010.08.013

[33] Ebnali, M., Hulme, K., Ebnali-Heidari, A. and Mazloumi, A. (2019) How Does Training Effect Users' Attitudes and Skills Needed for Highly Automated Driving? Transportation Research Part F: Traffic Psychology and Behaviour, 66, 184-195. https://doi.org/10.1016/j.trf.2019.09.001

[34] Ebnali, M., Kian, C., Ebnali-Heidari, M. and Mazloumi, A. (2020) User Experience in Immersive VR-Based Serious Game: An Application in Highly Automated Driving Training. In: Stanton, N., Ed., Advances in Human Factors of Transportation, Springer International Publishing, Berlin, 133-144.

https://doi.org/10.1007/978-3-030-20503-4_12

[35] Carfora, A., Campobasso, C.P., Cassandro, P., Petrella, R. and Borriello, R. (2018) Alcohol and Drugs Use among Drivers Injured in Road Accidents in Campania (Italy): A 8-Years Retrospective Analysis. Forensic Science International, 288, 291-296. https://doi.org/10.1016/j.forsciint.2018.05.003 